\title{
Atypical Infantile Familial Chylomicronemia Syndrome: A Milky Mess
}

\author{
Mir Inzamam Ali $^{1 *}$, Malay Jhancy ${ }^{2}$, Joel Thomas ${ }^{1}$, Mohammed Rahim ${ }^{1}$, and Abdullah Qabille ${ }^{1}$
}

${ }^{1}$ Student Researcher, RAK College of Medicine, UAE

${ }^{2}$ Professor, Department of Pediatrics, RAK College of Medicine, UAE

DOI: $10.36347 /$ sasjm.2020.v06i11.004

| Received: 20.12.2019 | Accepted: 27.12.2019 | Published: 20.11.2020

*Corresponding author: Mir Inzamam Ali

Abstract

Familial Chylomicronemia was formerly known as type 1 hyperlipoproteinemia, it is a type of severe hypertriglyceridemia characterized by the accumulation of chylomicrons in fasting plasma. Chylomicrons in a patient with health are responsible for carrying the absorbed Triglycerides (TG) into tissues via the activation of Lipoprotein Lipase (LPL) by Apo CII, thus causing the TG to be stored. In cases of Chylomicronemia, the TG is not carried into the tissue and stored thus increasing the level of Chylomicron carrying TG in plasma. This disease has a prevalence of 1 in 1 million for homozygotes and 1 in 500 for heterozygote. The most common mutations are found in the genes LPL, ApoA5, GPIHBP1, and ApoC2 among others. Loss-of-function mutation in these genes renders the LPLdependent pathway inefficient [1].

Keywords: Atypical infantile familial chylomicronemia.

Copyright $\odot 2020$ The Author(s): This is an open-access article distributed under the terms of the Creative Commons Attribution 4.0 International License (CC BY-NC 4.0) which permits unrestricted use, distribution, and reproduction in any medium for non-commercial use provided the original author and source are credited.

\section{INTRODUCTION}

Familial Chylomicronemia Syndrome (FCS) results from inactivating mutations in both alleles of the LPL gene in approximately $80 \%$ of genetically confirmed cases but can also result from mutations in other genes that are required for the correct localization and function of LPL (Illustration 1). LPL forms a homodimer and is biologically active on the luminal side of the capillary endothelium in adipose and muscle tissue. Intravenous injection of heparin releases LPL from the capillary endothelium allowing determination of LPL mass and activity. More than 180 pathogenic mutations have been described in the LPL gene, with some mutations clustering regionally secondary to founder effects. Apolipoprotein C-II (APOC2) is an essential activator of LPL and bi-allelic mutations in the APOC2 gene leads to functional LPL deficiency and phenotypic FCS. Apolipoprotein A-V (APOA5) also enhances the activity of LPL, and rare mutations in the APOA5 gene have been described as causing FCS, although penetrance is often incomplete and hypertriglyceridemia may be noted only later in life. Besides LPL gene mutations, mutations in genes involved in cellular processing and/or endothelial binding of LPL can also cause FCS. Lipase maturation factor 1 is involved in maturation and transport of LPL through the secretory pathway in endothelial cells and LPL is translocated across and subsequently anchored to the capillary endothelium by glycosylphosphatidylinositol-anchored high-density lipoprotein-binding protein 1 (GPIHBP1). Recently, it has been reported that autoantibodies targeting GPIHBP1 may also result in an FCS-like phenotype. Finally, a rare patient with a phenotype resembling that of FCS was found to have compound heterozygous mutations in the glucokinase regulator (GCKR) gene [2].

Gene ID on NCMI database discusses the function of a recently studied protein called Apolipoprotein C-III (Apo C3) which is similar to ApoC1. Apo C3 is metabolized in the liver and is a major structural component of VLDL, HDL, and chylomicrons. It acts as an inhibitor of LPL. Apo C3 was also found to inhibit hepatic uptake of chylomicrons and VLDL particles by interfering between the hepatic receptor-ApoE interactions. High plasma Apo C3 levels were also found in patients with high plasma triglyceride concentration [3]. Further in a report published in NEJM three patients with the familial chylomicronemia syndrome and triglyceride levels ranging from 1406 to $2083 \mathrm{mg}$ per deciliter (15.9 to $23.5 \mathrm{mmol}$ per liter) were administered an inhibitor of APOC3 messenger RNA (mRNA), called ISIS 304801. The aim of this study was to see the effect of Apo C3 on TG levels. 13 weeks after the administration of ApoC3 inhibitor it was found that plasma APOC3 
levels were reduced by 71 to $90 \%$ and triglyceride levels by 56 to $86 \%$. This data supports the important role of APOC3 as a key regulator of LPL-independent pathways of triglyceride metabolism [1].

Familial Chylomicronemia is often discovered incidentally by lactescent plasma during routine blood sampling. The age at presentation is usually in infancy or childhood with clinical sign/symptoms of episodes of eruptive xanthomas on the trunk and extremities, lipaemia retinalis, recurrent abdominal pain, acute and/or chronic pancreatitis and hepatosplenomegaly. The signs and symptoms when present are typical of this condition and makes diagnosis favorable but this is not true for all cases. According to a study by Nagar and Arora, LPL deficiency was demonstrated in 16 infants in Quebec, Canada it was noticed that not all infants presented with typical symptoms/signs. Some of the atypical features seen were heterogeneous features, irritability, pallor, anemia, and gastrointestinal bleed [4]. This was also demonstrated in case one where a 1 month old was accidentally found to have severe hypertriglyceridemia while being evaluated for pallor and jaundice. Due to the effect of this condition on liver and spleen seen clinically as hepatosplenomegaly, destruction of RBCs by the spleen was majority responsible for these atypical symptoms seen in infants [5]. This raises the concern of physician awareness to typical and atypical symptoms seen in FCS in infants versus adults.

It is important to diagnose this condition early on its course to prevent later complications such as acute - chronic pancreatitis and pancreatic necrosis. FCS can interfere with normal growth and development of infants and result in frequent hospitalizations. This condition can later lead to exocrine or endocrine pancreatic insufficiency, including diabetes [6]. Diagnosis is based on lipid profile evaluation and blood sampling. A lactescent (milky) plasma appearance and a serum triglyceride of $>1000 \mathrm{mg} / \mathrm{dl}$ are sufficient to make a diagnosis. TG are often 10 -fold to 100 -fold above the normal value $(<150 \mathrm{mg} / \mathrm{dl})$ and may range from 1500 to $>15,000 \mathrm{mg} / \mathrm{dL}$ [7].

Currently available triglyceride-lowering agents are not completely effective in controlling chylomicronemia in such patients. Recently an LPL gene-replacement therapy (Glybera), was approved in Europe but is not yet made available in the international market. Thus, patients in other countries, the only therapeutic approach is to effectively maintain triglyceride levels below $880 \mathrm{mg}$ per deciliter $(10 \mathrm{mmol}$ per liter), levels below this greatly reduce the risk of pancreatitis [8]. The most effective treatment modality is severe dietary triglyceride restriction. As compliance with such requirement if difficult, episodes of chylomicronemia presenting with abdominal pain and recurrent pancreatitis is quite common. Therefore, additional pharmacological therapies are required to maintain triglyceride levels below $880 \mathrm{mg}$ per deciliter [9].

Here we report a case 3- month- old presenting with atypical symptoms of FCS.

\section{CASE SCENARIO}

A 3-month-old infant was brought to the hospital by his parents with a 2-day history of high fever (39 C) which was associated with cough, breathlessness and s/o respiratory infection. He visited a local clinic with the same complaint prior to coming to the hospital. When blood was withdrawn for investigation, lactescent (milky) plasma was noted (Figure 1). Past history includes passage of blood in the stool at 20th and 21st day of the neonatal period, which was followed by spontaneous disappearance of blood on the 22nd day. There was no record of specific diseases running in the family members.

His vitals were: BP 106/84, RR 30/min, PR 126/min, Temperature $40 \mathrm{C}$ and anthropometric measures were: Head Circumference $41 \mathrm{~cm}$, Weight 4 $\mathrm{Kg}$, and Height of $63 \mathrm{~cm}$. Physical examination revealed a distended abdomen with hepatosplenomegaly (Figure 2). There were no fatty deposits (xanthomas) under the skin. Examination of other organs was unremarkable.

Lab Results revealed Serum cholesterol 361 $\mathrm{mg} / \mathrm{dl}(<170 \mathrm{mg} / \mathrm{dl})$, Serum triglycerides $2146 \mathrm{mg} / \mathrm{dl}$ $(<150 \mathrm{mg} / \mathrm{dl})$ and a VLDL of $429 \mathrm{mg} / \mathrm{dl}(<30 \mathrm{mg} / \mathrm{dl})$. Other investigations were Apo B 184 mg/dl (55-140 $\mathrm{mg} / \mathrm{dl})$, Apo A $100 \mathrm{mg} / \mathrm{dl}(110-225 \mathrm{mg} / \mathrm{dl})$, S. lipase $200 \mathrm{mg} / \mathrm{dl}(0-8 \mathrm{mg} / \mathrm{dl})$, S. amylase $11 \mathrm{U} / \mathrm{l}$, T3 1.78 $\mathrm{mg} / \mathrm{ml}$, T4 $11.98 \mathrm{mcg} / \mathrm{dl}$, TSH $2.78 \mu \mathrm{IU} / \mathrm{ml}, \mathrm{S}$. Ca 8.9 $\mathrm{mg} / \mathrm{dl}$, S. Phosphorus $3.0 \mathrm{mg} / \mathrm{dl}$, S. Uric acid $4.0 \mathrm{mg} / \mathrm{dl}$. Liver Function test results were Total bilirubin-0.8 mg/dl, SGOT- $22 \mathrm{u} / \mathrm{l}$, SGPT- $394 \mathrm{u} / \mathrm{l}$, and ALP- $56 \mathrm{u} / \mathrm{l}$. Fasting blood sugar was checked and was $84 \mathrm{mg} / \mathrm{dl}$. BUN was $21 \mathrm{mg} / \mathrm{dl}$, Serum Creatinine was $0.7 \mathrm{mg} / \mathrm{dl}$ and $\mathrm{CRP}$ was negative. $\mathrm{CBC}$ was done results were: WBC- 20,400/mm3, RBC- 3.47 million/mm3, HB- 9.6 gm\%, HCT- $28.3 \%$, PLT- 360000/mm3, MCV-81 mcm3, MCH-27 pg, MCHC-33 g/dl, and RDW-15.8\%. Ultrasonography showed increased size and echotexture of both liver and spleen suggesting hepatosplenomegaly (Liver- $9 \mathrm{~cm}$ in and spleen $-6.2 \mathrm{~cm}$ ) (Figure $4 \mathrm{~A}$ ). On $\mathrm{X}$-Ray Abdomen liver silhouette was enlarged, displacing bowel loops medially (Figure 4 B). Ophthalmological examination was done and revealed lipemia retinalis. Neurosonogram and Renal Doppler were normal. Lipid profile was done for the mother and father and revealed elevated levels of VLDL, TG and decreased levels of HDL.

The child was started on Simvastatin 10 mg/day, an HMG-CoA reductase inhibitor. Along with this dietary fat restriction and exclusive breastfeeding was advised. 
There are no FDA approved statins to use in this age group, in spite they were used in the management of this case. On Follow up after 1 year the patient had developed xanthomas on his right elbow and triglyceride levels were not significantly reduced.

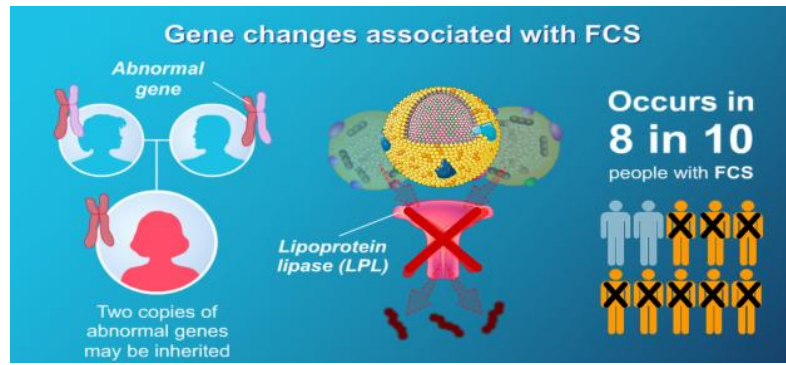

Fig-1: Gene changes associated with FCS

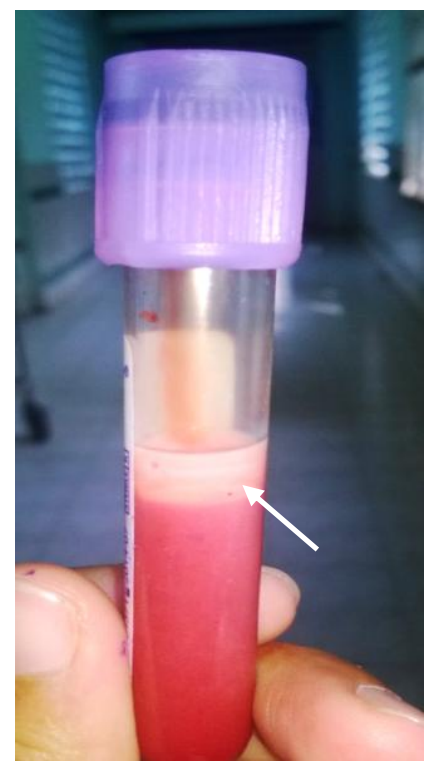

Fig-2: Lactescent Plasma

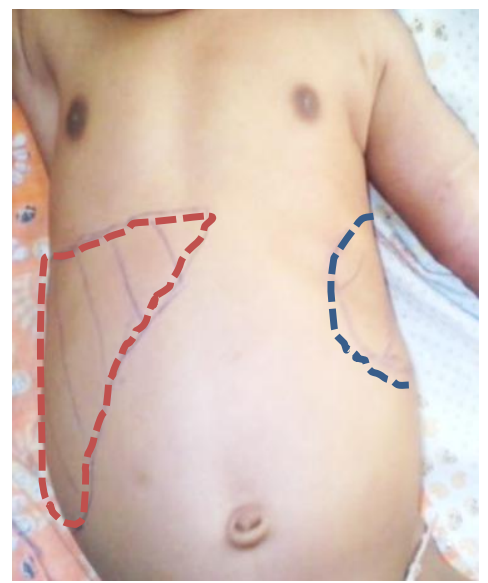

Fig-3: Distended abdomen with hepatosplenomegaly

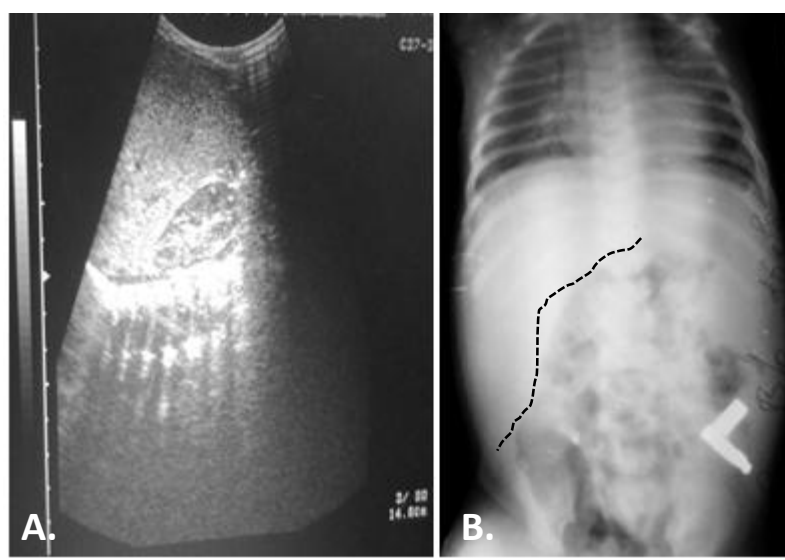

Fig-4: A. Ultrasound showing increased size and echotexture of Liver B. Liver silhouette is enlarged displacing bowel loops medially.

\section{DISCUSSION}

Familial Chylomicronemia Syndrome (FCS) is a rare, recessive genetic disorder caused by mutations in Lipoprotein Lipase (LPL) or genes required for LPL functionality. FCS is characterized by hyperchylomicronemia, recurrent abdominal pain, hepatosplenomegaly and recurrent episodes of acute pancreatitis that may result in pancreatic insufficiency along with atypical symptoms as mentioned before which are seen in infants. There are no FDA approved treatments for FCS and patients are managed with a low-fat diet. Due to the rarity of FCS there are few case series describing phenotypic variability in this disorder [10].

In a 2018 retrospective review done at the Cleveland Clinic, Ohio,70,201 patients that were seen at the Cleveland Clinic Lipid Center from 2006-2016 met the diagnostic criteria for FCS (TG>750 mg/dL. These patients were unresponsive to triglyceride-lowering treatment. They were then compared to patients with TG>750 mg/dL who did not meet criteria for FCS. A total of 36 patients were identified with hypertriglyceridemia and prior pancreatitis. Of those, 14 patients were identified as having FCS $(0.02 \%$ incidence). Patients with FCS were more likely to be male (79\% vs 55\%), have higher BMI (mean 32 vs 29, $\mathrm{p}<0.05$ ), and have lower Hb A1C (mean $6.7 \%$ vs $8.7 \%$, $\mathrm{p}<0.05)$. The lipid distributions were similar among both groups. Moreover, the risk of cardiovascular (CV) events was also similarly elevated (approximately 50\% by age 60) in both groups [11].

The high levels of circulating plasma Chylomicrons can accumulate at multiple locations, such as the skin, producing eruptive xanthomas, or in the retinal blood vessel (lipemia retinalis). The most life-threatening complication of FCS is the occurrence of severe and recurrent episodes of acute pancreatitis [12]. 


\section{Age-appropriate nutrition}

- $\quad$ 0-12 months: Low LCT, high MCT formula or skimmed and fortified expressed breast milk, Introduce low fat table foods when ageappropriate.

- 12-24 months: skim milk and low fat table foods as appropriate. Avoid concentrated sweets, including $100 \%$ fruit juice.

- Children and adolescents: continue to provide individualized counseling and modify diet as needed. Special considerations include fussy eating in children and compliance in adolescents [13].

Although control of diet and lifestyle, and management of secondary hypertriglyceridemia risk factors remain the current mainstay of treatment for primary chylomicronemia, the increased understanding of the molecular features that lead to the chylomicronemia state have facilitated the development of targeted therapies. Among the new therapies, LPL gene therapy is the most specific to the underlying genetic disorder; however, MTTP and DGAT1 inhibitors, antisense oligonucleotides directed against APOB, APOC3 and ANGPTL3 mRNAs, as well as other targeted pharmacological agents in development, might also prove useful in the treatment of both monogenic chylomicronemia (which up until now has been an orphan disease with no effective treatment options) and the polygenic form. Close attention must be given to the outcomes of the clinical trials that are ongoing for these agents and their possible role in the management of FCS [14].

\section{CONCLUSION}

FCS is a serious inherited lipid disorder associated with chronic, life-altering consequences. Early diagnosis is essential to prevent morbid sequelae of complications such as Acute/Chronic pancreatitis or pancreatic necrosis. Statins should be indicated in the treatment of FCS along with dietary fat restriction. More research should be made for the management of such cases. Consensus on best practice for the diagnosis of FCS is lacking. Cooperation between experts and improved research and knowledge of FCS is essential in improving the diagnosis.

\section{REFERENCES}

1. Gaudet D, Brisson D, Tremblay K, Alexander VJ, Singleton W, Hughes SG, Geary RS, Baker BF, Graham MJ, Crooke RM, Witztum JL. Targeting APOC3 in the familial chylomicronemia syndrome. New England Journal of Medicine. 2014 Dec 4;371(23):2200-6.

2. Blom D, Alexander V, Digenio A, Baum S, Hemphill L, Santos R, Prokopczuk E, MunizGrijalvo O, Witztum J, Gaudet D. Characterizing familial chylomicronemia syndrome: baseline data of the APPROACH study. Journal of Clinical Lipidology. 2017 May 1;11(3):816.

3. APOC3 apolipoprotein C3 [Homo sapiens (human)] Gene ID: 345 available at https://www.ncbi.nlm.nih.gov/gene/345

4. Nagar R, Arora U. An unusual case of familial hyperlipidaemia. Indian $\mathrm{J}$ Clin Biochem. 2008;23(3):302-304

5. Chaurasiya OS, Kumar L, Sethi RS. An infant with milky blood: an unusual but treatable case of familial hyperlipidemia. Indian Journal of Clinical Biochemistry. 2013 Apr 1;28(2):206-9.

6. Brunzell JD, Deeb SS. Familial lipoprotein lipase deficiency, apo CII deficiency and hepatic lipase deficiency In: Scriver CR, Beaudet AI, Sly WS, Valle D, eds. The metabolic and molecular basis of inherited disease. 8th ed. New York: McGraw-Hill, 2000:2789-816.

7. Williams L, Rhodes K, Karmally W, Welstead L, Alexander L, Sutton L. Familial chylomicronemia syndrome: Bringing to life dietary recommendations throughout the life span. Journal of Clinical Lipidology. 2018;12(4):908-919.

8. Gaudet D, Méthot J, Déry S, Brisson D, Essiembre C, Tremblay G, Tremblay K, de Wal J, Twisk J, van den Bulk N, Sier-Ferreira V. Efficacy and long-term safety of alipogene tiparvovec (AAV1LPL S447X) gene therapy for lipoprotein lipase deficiency: an open-label trial. Gene therapy. 2013 Apr;20(4):361.

9. Clauss SB, Kwiterovich PO. Genetic disorders of lipoprotein transport in children. Prog Pediatr Cardiol. 2003;17(2):123-133.

10. Rhodes KS, Williams L, Alexander L, Karmally W, Welstead LA, Sutton L. Familial Chylomicronemia Syndrome (FCS): Medical Nutrition Therapy Guidelines for Patients and Healthcare Providers. Atherosclerosis Supplements. 2018 Jun 1;32:135.

11. Shah N, Hazen S, Cho L, Ahmed H. Familial chylomicronemia syndrome: an insight into its clinical characteristics and long term cardiovascular outcomes. Journal of the American College of Cardiology. 2018 Mar 10;71(11 Supplement):A1779.

12. Stroes E, Moulin P, Parhofer KG, Rebours V, Löhr JM, Averna M. Diagnostic algorithm for familial chylomicronemia syndrome. Atherosclerosis Supplements. 2017 Jan 1;23:1-7.

13. Williams L, Wilson DP. Editorial commentary: Dietary management of familial chylomicronemia syndrome. J Clin Lipidol. 2016;10:462-465

14. Brahm AJ, Hegele RA. Chylomicronaemiacurrent diagnosis and future therapies. Nature Reviews Endocrinology. 2015 Jun;11(6):352. 